\title{
Review Article \\ Chimeric Antigen Receptor-Modified T Cells for Solid Tumors: Challenges and Prospects
}

\author{
Yelei Guo, Yao Wang, and Weidong Han \\ Department of Immunology, Institute of Basic Medicine, Chinese PLA General Hospital, Beijing 100853, China \\ Correspondence should be addressed to Weidong Han; hanwdrsw69@yahoo.com
}

Received 20 October 2015; Revised 18 December 2015; Accepted 28 January 2016

Academic Editor: Kurt Blaser

Copyright ( 2016 Yelei Guo et al. This is an open access article distributed under the Creative Commons Attribution License, which permits unrestricted use, distribution, and reproduction in any medium, provided the original work is properly cited.

\begin{abstract}
Recent studies have highlighted the successes of chimeric antigen receptor-modified T- (CART-) cell-based therapy for B-cell malignancies, and early phase clinical trials have been launched in recent years. The few published clinical studies of CART cells in solid tumors have addressed safety and feasibility, but the clinical outcome data are limited. Although antitumor effects were confirmed in vitro and in animal models, CART-cell-based therapy still faces several challenges when directed towards solid tumors, and it has been difficult to achieve the desired outcomes in clinical practice. Many studies have struggled to improve the clinical responses to and benefits of CART-cell treatment of solid tumors. In this review, the status quo of CART cells and their clinical applications for solid tumors will be summarized first. Importantly, we will suggest improvements that could increase the therapeutic effectiveness of CART cells for solid tumors and their future clinical applications. These interventions will make treatment with CART cells an effective and routine therapy for solid tumors.
\end{abstract}

\section{Introduction}

Recently, chimeric antigen receptor-modified T- (CART-) cell-based therapy, an innovative approach to tumor treatment, was demonstrated to potentially exhibit MHCindependent antitumor effects. These cells could directly recognize tumor cells by genetic modification to express a chimeric antigen receptor (CAR), and they were activated to exhibit a durable persistence in vivo through the T-cell activation endodomain with costimulatory signaling molecules $[1$, 2]. After two decades of preclinical research and clinical trials, the safety and feasibility of CART-cell-based therapy have been confirmed, and unprecedented clinical results have been obtained in hematological malignancies [3-5]. For example, several groups have reported clinical trials with anti-CD19 CART cells in which favorable clinical efficacy resulted from the specific recognition and eradication of CD19-positive tumor cells $[3,4,6]$. These clinical studies indicate that CART-cell therapy can produce clinical responses in patients with advanced hematological malignancies.

The clinical studies of CART cells for solid tumors have begun recently. Up to date, eleven studies of CART-cell therapy for solid tumors have been conducted in the past decade (Table 1), and thirty-five clinical trials for various solid tumors are listed at ClinicalTrials.gov (http://www.clinicaltrials.gov) (Figure 1). The registered numbers of clinical trials increase annually, and a range of tumor antigens, including CEA, mesothelin, HER2, and GD2, are being targeted for various solid tumors.

In preclinical studies, antitumor efficacy of CART cells has been confirmed in vitro and in animal experiments; however, the clinical outcomes in recent studies of CART cells treating solid tumors remain marginal, even though the safety and feasibility have been established [7-9]. Recently, several studies have attempted to search efficient approaches to improve the effectiveness of CART cells for solid tumors. In this review, we discuss the main challenges that impede the development of favorable clinical responses in solid tumors, and we suggest improvements for future clinical applications of CART cells.

\section{A Concise History of the Clinical Applications of CART Cells in Solid Tumors}

CAR redirected T-cell-based therapy has emerged as a promising strategy for malignant diseases since the first 
TABLE 1: Recent published clinical studies on CART cells specific for solid tumor antigens.

\begin{tabular}{|c|c|c|c|c|c|c|c|}
\hline Antigen & CAR & Gene transfer & Cancer & Case number & $\begin{array}{c}\text { Clinical } \\
\text { outcome }\end{array}$ & Time & Reference \\
\hline HER2 & $\mathrm{ScFv}-\mathrm{CD} 28-\mathrm{CD} 3 \zeta$ & Retrovirus & HER2-positive sarcoma & 19 & $1 \mathrm{PR}, 4 \mathrm{SD}$ & 2015 & {$[15]$} \\
\hline CEA & $\mathrm{ScFv}-\mathrm{CD} 28-\mathrm{CD} 3 \zeta$ & Retrovirus & $\mathrm{CEA}+$ liver metastases & 8 & $1 \mathrm{SD}, 5 \mathrm{DOD}$ & 2015 & [17] \\
\hline Mesothelin & ScFv-4-1BB-TCR $\zeta$ & Electrotransfer & Mesothelioma & 2 & $1 \mathrm{PR}, 1 \mathrm{SD}$ & 2014 & {$[14]$} \\
\hline Mesothelin & ScFv-4-1BB-TCR $\zeta$ & Electrotransfer & Mesothelioma & 1 & $1 \mathrm{PR}$ & 2013 & {$[16]$} \\
\hline CAIX & ScFv-FceRI $\gamma$ & Retrovirus & CAIX+ metastatic RCC & 12 & NED & 2013 & {$[8]$} \\
\hline GD2 & $\mathrm{ScFv}-\mathrm{CD} 3 \zeta$ & Retrovirus & Neuroblastoma & 19 & $3 \mathrm{CR}, 1 \mathrm{PR}$ & 2011 & {$[5]$} \\
\hline $\mathrm{ERBB}^{*}$ & ScFv-CD28-4-1BB-CD3 & Gamma-retrovirus & Colon cancer & 1 & Dead & 2010 & {$[13]$} \\
\hline GD2 & $\mathrm{ScFv}-\mathrm{CD} 3 \zeta$ & Retrovirus & Neuroblastoma & 11 & $\begin{array}{l}1 \mathrm{CR}, 2 \mathrm{SD}, 2 \\
\text { tumor necrosis }\end{array}$ & 2008 & {$[12]$} \\
\hline CD171 & $\mathrm{ScFv}-\mathrm{CD} 3 \zeta$ & Electrotransfer & Neuroblastoma & 10 & $1 \mathrm{PR}$ & 2007 & [9] \\
\hline FR & $\mathrm{ScFv}-\mathrm{FccRI} \gamma$ & Retrovirus & Ovarian cancer & 8 & NED & 2006 & {$[11]$} \\
\hline CAIX & ScFv-FceRI $\gamma$ & Retrovirus & CAIX+ metastatic RCC & 3 & NED & 2006 & [7] \\
\hline
\end{tabular}

CAIX: carboxy-anhydrase-IX; CEA: carcinoembryonic antigen; CR: complete response; DOD: dead of disease; FR: folate receptor; HER2: human epidermal growth factor receptor 2; NED: no evidence of disease; PR: partial response; RCC: renal cell carcinoma; ScFv: single chain fragment of variable region antibody; SD: stable disease.

${ }^{*}$ HER2/neu.

report by Gross et al. in 1989 [10]. In the past two decades, several studies have demonstrated encouraging clinical outcomes in patients with B-cell malignancies that are treated by CART cells, and the results from these studies indicated that CART cells could produce clinical responses in other types of cancer $[3,4,6]$. Theoretically, CART-cell therapy could be curative for solid tumors if the genetically modified $\mathrm{T}$ cells encountered the tumor cells in vivo. Accordingly, the development of CART cells for solid tumors is imperative in the clinic. Nevertheless, there are few reports of successful clinical studies of solid tumors that are treated with CART cells.

Thus far, CART-cell-based therapy has been tested against several types of solid tumors, including ovarian cancer, neuroblastoma, colon cancer, and mesothelioma (Table 1) [11-14]. In the first clinical study, three patients with metastatic renal cell carcinoma who were administered CART cells specific for CAIX developed liver toxicity [7]. And a further trial of 12 patients treated with anti-CAIX CART cells is still ongoing to assess the safety of the cells [8]. Further initial reports demonstrated encouraging outcomes in 30 patients with neuroblastoma treated with CART-GD2 cells $[5,12]$. A clinical study of neuroblastoma from another center used CD171-specific CART cells and indicated some evidence of antitumor efficacy [9]. Importantly, these studies show that CART-cell therapy is safe for patients with advanced solid tumors, but the use of first-generation CART cells and their limited survival may account for the lack of a spectacular clinical response.

To enhance the persistence of CART cells and improve the clinical outcome in solid tumors, costimulators, such as CD28, 4-1BB, and OX40, were integrated into the fusion CAR protein $[13,15,16]$. In one case report, a patient with colon cancer that metastasized to the lungs and liver, who received conditioning lymphodepletion and was treated with $10^{10}$

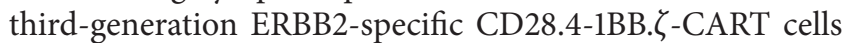
combined with IL-2, developed acute respiratory distress syndrome and died five days after the treatment [13]. In another study, sarcoma patients treated with up to $10^{8} / \mathrm{m}^{2}$ second-generation CART cells encoding a HER2.CD28. $\zeta$ CAR without conditioning chemotherapy or administration of IL-2 experienced no toxicity, but the antitumor effect was limited [15]. Several other clinical studies with CEAand mesothelin-specific second-generation CART cells for solid tumors have been reported recently, and the safety and efficacy of this cell-based therapy have been confirmed $[14,16,17]$.

Taken together, the clinical experience with CART-cell therapy for solid tumors suggests that several factors, including the tumor antigens, costimulatory molecules, CARTcell development process, and conditioning therapies, likely contributed to the different clinical outcomes. Thus, several urgent issues need to be resolved to improve the safety and clinical responses of CART cells for patients with solid tumors.

\section{Potential Challenges for CART-Cell Treatment of Solid Tumors in the Clinic}

Although CART-cell-based therapy has been shown to be a potential treatment strategy for few solid tumors [14, 15, 17], the challenges to this strategy that affect safety and clinical outcomes should be addressed. The current critical issues are discussed in the following.

3.1. The Screening of Solid Tumor Target Antigens. Preclinical studies on CART cells that are specific for many different tumor antigens expressed on solid tumors have been conducted and have shown antitumor effects $[18,19]$. To date, numerous potential solid tumor target antigens have been explored for CART-cell-based therapy (Table 2), but unfortunately, few antigens are uniquely specific for solid 


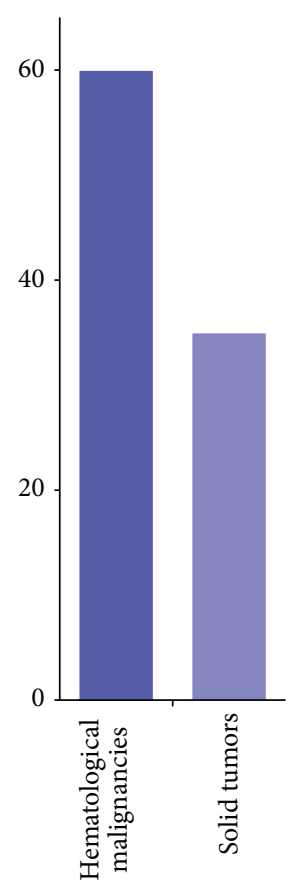

(a)

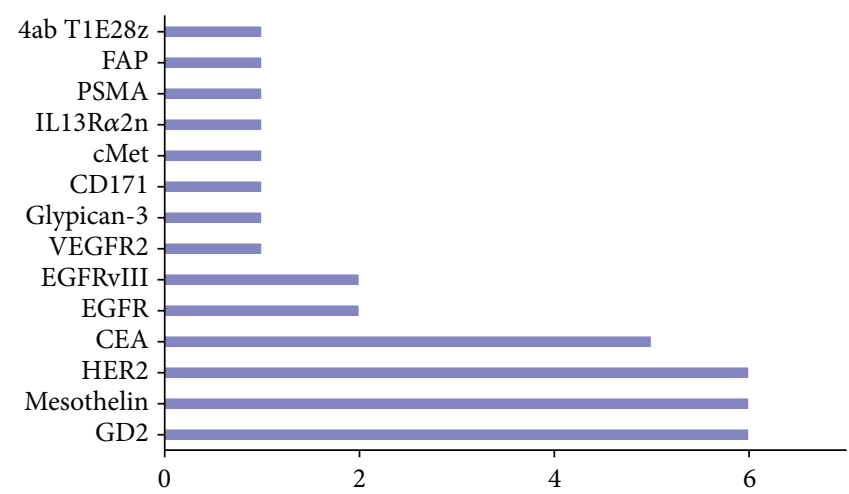

(b)

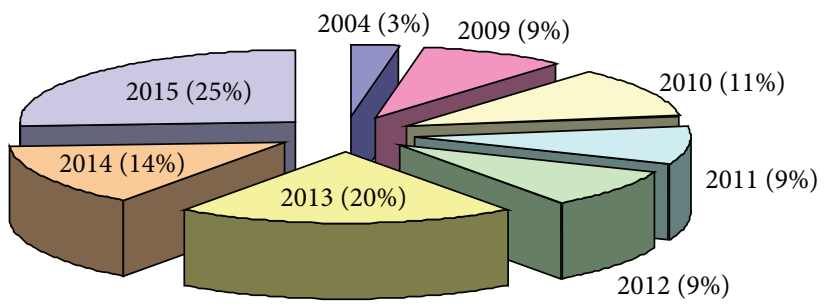

(c)

FIgURE 1: Current status of clinical trials of chimeric antigen receptor-modified T (CART) cells in malignancies. These data were searched on 15 June, 2015, from the website ClinicalTrials.gov (http://www.clinicaltrials.gov). The key phrases "chimeric antigen receptor-modified T cells", "chimeric antigen receptor", "CART", and "CAR" were used. (a) Comparison of the number of registered CART-cell trials for solid tumors and hematological malignancies on the ClinicalTrials.gov website. (b) The registered solid tumor targets for CART cells on the ClinicalTrials.gov website. EGFR: epidermal growth factor receptor; FAP: fibroblast activation protein; PSMA: prostate-specific membrane antigen; VEGFR2: vascular endothelial growth factor receptor 2. (c) Proportion of annual registered numbers of CART cells in solid tumors on the ClinicalTrials.gov website.

tumors. A major concern of CART cells in solid tumor treatments is ensuring the effective elimination of tumor cells while avoiding the off-tumor/on-target toxicity that caused when these T cells attack healthy tissues. Experience indicates several principles that should be observed to overcome this problem: (1) preferred selection of specific tumor antigens and (2) selection of tumor targets based on their expression level and frequency on tumor and normal tissues [20, 21]. The density of tumor antigen expression can also affect the selection of CART-cell targets [22].

In addition, it is well known that tumor-associated antigens can be divided into two groups, including mutated antigens (also called neoantigens) and "self-" antigens such as tissue/lineage antigens, developmental antigens, and overexpressed antigens [23]. Most of the recent studies have indicated that cancer immunotherapies have remained focused on recognizing "self-" antigens; however, only few immunotherapies target neoantigens [24, 25]. Neoantigens, short 8 to 12 amino acid peptides that are known to be created by cancer cell genomes mutations, can be rapidly identified by high-throughput next-generation sequencing (NGS) in several cancers, including melanoma, ovarian cancer, and cholangiocarcinoma [19-26]. In contrast to "self-" antigens that are expressed on tumor and normal cells, neoantigens are only found in tumor cells, showing accurate specific targets for cancer immunotherapy to reduce the risk for autoimmune disease, for example, a splice variant of the epidermal growth factor receptor (EGFRvIII) [26, 27]. Based on their specific features, recent clinical evidence has confirmed that neoantigens are the best potential targets for adoptive $\mathrm{T}$ cell therapy with least possible toxicity [28]. Therefore, it is reasonable that a strategy using CART cells that specifically target neoantigens is the best potential therapeutic treatment for cancers without severe target-mediated toxicity. 
TABLE 2: Potential solid tumor targets for CART cell-based therapy.

\begin{tabular}{lc}
\hline Antigen & Cancer \\
\hline CD44v7/8 & Cervical carcinoma \\
DNAM-1 & Prostate carcinoma \\
EGP-40 & Colorectal cancer \\
EpCAM & Prostate cancer \\
FBP & Ovarian cancer \\
FR & Rhabdomyosarcoma \\
GD3 & Melanoma \\
VEGFR2 & Tumor neovasculature \\
LMP-1 & PVR and nectin-2 expressing solid tumors \\
MUC1 & Breast, ovary \\
PSCA & Melanoma, synovial cell sarcoma \\
\hline
\end{tabular}

DNAM-1: DNAX accessory molecule-1; EGP-40: epithelial glycoprotein40; EpCAM: epithelial cell adhesion molecule; FBP: folate-binding protein; LMP-1: latent membrane protein 1; MUC1: mucin 1; PSCA: prostate stem cell antigen.

3.2. Optimizing the Affinity of the CAR. The affinity of CAR is also important for its antitumor effect and target-mediated toxicity. The relationship among the CAR affinity and density and tumor antigen density could impact the effector function of CART cells. Low affinity was more effective than highaffinity CAR under conditions when the levels of CAR were limiting, whereas no significant difference was observed on the variance of CAR affinity on conditions of high levels of CAR expression [29]. In addition, high-affinity CAR did not increase the activity of $\mathrm{T}$ cells against target tumor cells compared with low CAR affinity, and the high-affinity CAR distinguished less well between tumor cells with high or low levels of antigen expression, whereas low affinity CAR showed negligible responses to tumor antigens expressed at low or undetectable levels, but they were highly reactive to the tumor cells that overexpressed antigen $[30,31]$. A recent study on the sensitivity of CAR to EGFR density indicated that CAR with reduced affinity could render CART cells able to distinguish tumor from normal tissues, and their antitumor effects were decreased along with the reduced density of EGFR [32]. On the basis of the careful conclusions from previous studies on solid tumors, it is possible to select the reduced affinity of CAR to avoid the off-tumor/on-target toxicity when target antigens are overexpressed on tumor cells and expressed at low levels in normal tissues. However, for highly specific tumor antigens, high-affinity CAR should be considered to prevent tumor escape when tumor cells express a low level of antigens.

3.3. The Source of the Single-Chain Fragment of the Variable Region Antibody (scFv). Most existing studies have derived the $\mathrm{scFv}$ components of the chimeric receptor from mouse monoclonal antibodies $[11,33]$. Although this construct only contains the variable regions of the mouse monoclonal antibody, a human anti-mouse antibody by the recipient could, after cell infusion, block the interaction between CAR and the target tumor antigen to inhibit the antitumor effect of the CART cells. The use of humanized scFvs or scFvs derived from human monoclonal antibodies for CAR will solve this issue. Advances in biotechnology will expand the prospects for humanized scFvs for CART-cell-based therapy for solid tumors.

3.4. Costimulatory Molecules. To improve the expansion of CART cells in solid tumors, costimulatory molecules, including CD28 and 4-1BB, have also been incorporated in the CAR gene by several groups, with increased persistence in vivo $[14,15,17]$. Recent studies indicated that CD28 can accelerate T-cell expansion, leading to T-cell exhaustion and reduced cell persistence compared with the 4-1BB domain [34]. Additionally, it has been reported that $4-1 \mathrm{BB}$ is superior to $\mathrm{CD} 28$ costimulation because $4-1 \mathrm{BB}$ preferentially promotes the expansion of memory $\mathrm{T}$ cells, whereas CD28 expands naïve T cells [35]. However, other studies showed that there was no any clear superiority for either CD28- or 4-1BB-based CART cells. For example, no significantly different cytotoxicity in vitro and in vivo was observed on CART cells with either a CD28 or 4-1BB costimulator, although CD28-based CART cells produced higher IL-2, IL-6, and IFN-gamma levels [36]. Other studies showed that the expansion and antitumor cytotoxicity by CD28- and 4-1BB-based CART cells were similar [37]. In addition, Hombach et al. demonstrated that CD28-CART cells were superior to CD28-OX40-CART cells because the CD28-OX40 super-costimulation increased activation-induced cell death (AICD) and reduced the cells' antitumor function [38]. In contrast, some studies indicated that the CAR gene containing two costimulators, such as CD28 and 4-1BB, yielded improved T-cell survival and cytotoxicity compared with a single co-stimulator [37, 39]. After careful consideration, these studies indicate that the choice of costimulatory molecules affects the therapeutic response, but it remains unclear whether any costimulatory molecule is superior to another $[40,41]$. Therefore, more attempts to develop CAR with different costimulatory molecules are urgently needed to further explore the therapeutic outcomes in vitro and in vivo.

Here, some suggestions for the choice of costimulatory molecules will be delineated for solid tumors. For solid tumors, the migration to the tumor sites is a prerequisite for CART cells to play an antitumor efficacy. Once breaking through the tumor microenvironment and making contact with target cells, CART cells need to undergo rapid expansion to have an antitumor function, while avoiding inhibition by the tumor environment. In clinical trials, for example, CD28 was associated with faster expansion than 4-1BB costimulation, and multiple cycles of infusion could overcome the shorter persistence of CD28-based CART cells in solid tumors.

\subsection{The Optimal Processing of T Cells Specific for Solid Tumors.} The response of solid tumors to CART cells in clinical studies has been limited [7-9]. These suboptimal outcomes could reflect the use of first-generation CART cells with a low ability to persist. Costimulation by integrating CD28 or 4-1BB into CAR molecules can improve the persistence of CART cells in vivo [42-44]. Moreover, the differentiation states (e.g., naïve 
$\mathrm{T}$ cells) and replicative frequencies of $\mathrm{T}$ cells could be key to achieving better clinical outcomes [45-47]. Previous studies have indicated that the stimulus and cytokine environment in the cell culture process can determine the T-cell differentiation state. For example, IL-7, IL-15, and IL-21 could slow T-cell differentiation $[48,49]$, whereas activation by soluble antiCD3 and CD28 monoclonal antibodies achieved optimal Tcell differentiation [50]. Activation by soluble anti-CD3 and CD28 monoclonal antibodies in the presence of IL-15 and IL21 enhanced $\mathrm{T}$ cells with a naïve phenotype and with a lower proportion of $\mathrm{CD} 4^{+} \mathrm{CD} 25^{+} \mathrm{CD} 127^{-}$expression [47].

Trafficking to and accumulating in the tumor sites are prerequisites for CART cells to play an antitumor efficacy, particularly for solid tumors. Nevertheless, CART cells cannot easily contact with target tumor cells due to the tumor microenvironment, resulting in the inability of these infused cells to fully activate and proliferate. T-cell migration to tumor sites requires integrins, chemokines, and chemokine receptors [51, 52]. However, cell culture in vitro and genetic modification could cause the loss of chemokine receptors, possibly resulting in CART cells being unable to localize accurately to the tumor tissues [53]. In previous studies, chemokine receptors, such as CXCR2 and CCR4, were genetically modified to be expressed on $\mathrm{T}$ cells to enhance their homing and antitumor activity $[54,55]$. Therefore, the forced expression of integrins, chemokines, and chemokine receptors on CART cells could improve their migration ability and promote their antitumor activity.

3.6. Preconditioning Therapy. Immunotherapy is a promising and efficient approach to cancer treatment. Basic research and clinical studies indicate that only a fraction of patients achieve durable clinical responses after immunotherapy. The immune system is highly important for maintaining a balance between protection from tumor development and the promotion of tumor growth, whereas tumor cells can escape the immune system leading to cancer progression that is facilitated by the tumor microenvironment when the balance is destroyed [56, 57]. The microenvironment of solid tumors has been reported to interfere with the desired clinical outcome through multiple networks of cellular interactions, which could create immune tolerance and negate immunotherapies, including CART-cell-based therapy. The tumor microenvironment is extremely complex and contributes to tumorigenesis and metastasis by limiting immune responses to cancer cells and preventing the eradication of tumors [58]. Interference with immune cell infiltration, activation, and proliferation in the tumor microenvironment can ultimately facilitate tumor development, metastasis, and resistance to therapy. Therefore, strategies to counteract the tumor microenvironment and to enhance antitumor effects are urgently needed.

Immunosuppressive cells (e.g., regulatory T lymphocytes, Tregs) can be induced to accumulate in tumor site by the tumor microenvironment, playing an essential role in tumorigenesis [59]. Preconditioning therapy to remove Tregs can effectively enhance the antitumor effects of CART cells for solid tumors. Fortunately, chemotherapy can make the tumor microenvironment highly permissive for antitumor immunity [60]. Chemotherapeutic agents, such as cyclophosphamide, docetaxel, and pemetrexed, could impair Treg function and enhance the host's immunity in clinical studies [6163]. Other strategies have been explored to reduce Tregs. For example, denileukin diftitox, an IL-2-diphtheria toxin fusion protein, directly killed Tregs through selective targeting of CD25 in preclinical cancer models [64]. A high-dose of IL-2 could downregulate the level of Tregs, at least in the periphery [65].

In addition, previous studies demonstrated that lymphodepleting chemotherapy preconditioning could enhance the antitumor efficacy of tumor-infiltrating lymphocytes [66]. Lymphodepletion creates an appropriate "lymphoid space" for the proliferation of adoptive infused immune cells. Additionally, lymphodepleting conditioning can improve the expansion and persistence of CART cells in solid tumor patients.

To the best of our knowledge, radiotherapy commonly induces tumor cell death through cell stress by altering cellular survival, and by apoptosis pathways and cell cycle regulatory mechanisms [67]. However, preclinical studies have also indicated that radiotherapy can make tumor cells more immunogenic by several mechanisms [68-70]. First, radiotherapy can make the tumor microenvironment more susceptible to attack by immune cells [71]. Second, tumor antigen expression is increased after local treatment by radiotherapy [72]. Third, radiotherapy could induce intratumoral dendritic cells expressing chemokines that attract immune cells into tumor sites [73, 74]. Finally, Fas, ICAM-1, and NKG2D ligands were upregulated on tumor cells after radiotherapy [75-77]. Based on this information, radiotherapy could play a role in enhancing adaptive antitumor effects, in addition to promoting the regression of tumors. Therefore, the antisolid tumor effects of CART cells could be enhanced by radiotherapy.

\section{Strategy of CART Cells Specific for Tumor Stroma}

Immunotherapy aims to improve the clinical antitumor response of cancer patients. Nevertheless, for many immunotherapies, the tumor microenvironment is the major barrier to an antitumor response [78]. Tumor stroma, a composition of the tumor microenvironment, could support tumor growth and resistance to therapy by the following mechanisms [67, 79-84]: (1) blocking therapeutic agents that attack tumor cells; (2) producing growth factors, chemokines, and matrix that could support tumor growth, invasion, and angiogenesis; (3) expressing inhibitory surface molecules such as programmed death-1 ligand (PD-L1) and PD-L2, producing factors to attract Tregs, myeloid-derived suppressor cells, and macrophages, and secreting factors to regulate T-cell functions to create an immunosuppressive milieu to inhibit immune cell function; and (4) the mechanisms of tumorigenesis that are supported by stroma coexisting among a variety of stromal cell types.

The most recent clinical studies see CART cells as attacking tumor cells. However, there can be limitations to the use of 
CART cells that are specific for solid tumors as, for example, tumor stroma, which could create bias towards an undesirable clinical response, compared with the considerable success in the treatment of hematologic malignancies. CART cells might not activate and proliferate well due to the tumor stroma inhibiting immune cells from making contact with tumor cells. Therefore, a strategy to disrupt the tumor stroma could improve the antitumor function of immunotherapy. CART cells that are specific for tumor stroma could promote the treatment of a broad spectrum of solid tumors.

To date, four attempts using CART cells that are specific for the fibroblast activation protein (FAP) that is highly expressed in cancer-associated stroma cells have been reported in animal models [85-88]. Antitumor activity was observed after CART-cell administration in these studies, although adverse events, such as on-target toxicity, were also observed because FAP is also expressed on normal tissues, including pancreas, lung, and bone marrow $[85,88]$. The on-target/off-tumor toxicity occurred because the scFv that targeted mouse stroma caused the CART cells to attack normal mouse stroma cells $[85,88]$. In contrast, other studies employing CART cells derived from human $\mathrm{T}$ cells and a $\mathrm{scFv}$ that targeted mouse or mouse/human stroma had no adverse events $[86,87]$. More importantly, the antitumor efficacy of the endogenous immune cell antitumor response was augmented by the CART-cell infusion; the CART cells lost their antitumor effect in immunodeficient mice [88].

Based on the data from the preclinical studies, CART cells that target tumor stroma could be candidates for solid tumor treatment in the future. However, several issues should be addressed before their clinical application: (1) the selection of the tumor stroma cell antigen; (2) the development of protocols to augment the antitumor effect for CART cells by combination with other immunotherapies, such as CART cells that are specific for tumor cells; and (3) the concern for potential adverse events such as on-target/off-tumor toxicity.

\section{Novel Concept of CAR Design for the Precision Treatment in Solid Tumors}

Tumor antigens are important to activate CART cells to induce immune activity against tumor cells. Nevertheless, solid tumor cells typically express highly heterogeneous tumor-associated antigens, rendering them able to escape detection by the immune system [89]. Only few antigens are tumor-specific for the treatment of solid tumors using CART cells. Although recent clinical studies indicated that CART cells were safe and feasible for solid tumors, ontarget/off-tumor toxicity remains the main concern impacting their clinical application. Accordingly, novel concepts of CAR design for solid tumor precision treatment have been explored to enhance the on-tumor specificity. Recently, several studies indicated that bispecific CAR design could improve the tumor cell specificity and limit the targetmediated toxicity of CART cells. Contrary to conventional CART cells that only target a single antigen, bispecific
CART cells can recognize multiple antigens by expressing two CARs on genetically modified T cells. For example, in preclinical models, $\mathrm{T}$ cells expressing two CAR molecules specific for PSMA and PMCA specifically targeted prostate cancer cells, and they were only activated in the presence of both antigens, not by either alone [90]. Another concept of bispecific CAR design uses a negative signal to enhance the tumor specificity: in one example a cytotoxic T lymphocyte antigen-4- (CTLA-4-) or programmed death-1- (PD-1-) based antigen-specific inhibitory CAR (iCAR) was designed to preemptively constrain T cells' responses [91]. These T cells selectively limited their cytokine secretion, cytotoxicity, and proliferation in response to normal tissues on which the iCAR was present. Bispecific CART cells, expressing a CAR and an iCAR specific for an antigen present on normal tissues, could avoid a CART-cell-mediated attack on normal tissues, consequently enhancing tumor specificity [91, 92]. In addition, the tandem CAR (TanCAR) design, which is also a bispecific CAR, can recognize each antigen and improve the activation and effective function when it encounters both antigens simultaneously using a single CAR molecule with two antigen recognition moieties that are joined in tandem [93]. The novel concept of CAR design to genetically modify $\mathrm{T}$ cells to target multiple tumor antigens could avoid the risk of immune escape [94]. This approach can also protect normal tissues by increasing the tumor specificity of CART cells. Ultimately, we must optimize the testing of bispecific CART cells to ensure their safety and efficacy before their clinical application for solid tumors.

In addition, to reverse on-target/off-tumor toxicity, several attempts to encode suicide genes in CART cells have shown that this adverse event can be irreversibly prevented through the selective destruction of the infused genetically modified T cells [95-97]. The addition of suicide genes to CART cells could ensure their safety for solid tumor treatments, avoiding unwanted and severe adverse events and increasing on-tumor specificity.

The precision treatment for solid tumors is improving more rapidly due to advances in biotechnology development (Figure 2). Recent advances in CART-cell-based therapy are currently being translated from the laboratory to the clinic. Novel concepts of CAR design could ensure the clinical application of CART cells for solid tumors with enhanced tumor specificity. Coupled with individual and diversified interventions (such as chemotherapies and vaccines), the precision of CART cells could provide great promise for the treatment of solid malignant patients in the future.

\section{Combinatorial CART-Cell Therapy to Improve Clinical Benefit in Solid Tumors}

The ultimate goal of cancer therapy is to be curative, including CART-cell immunotherapy. However, for solid tumors, the microenvironment is the major barrier to treatment with immunotherapy. It is necessary to develop a potent product to prevent the suppressive function of the solid tumor microenvironment to enhance the antitumor activity of CART-cell 


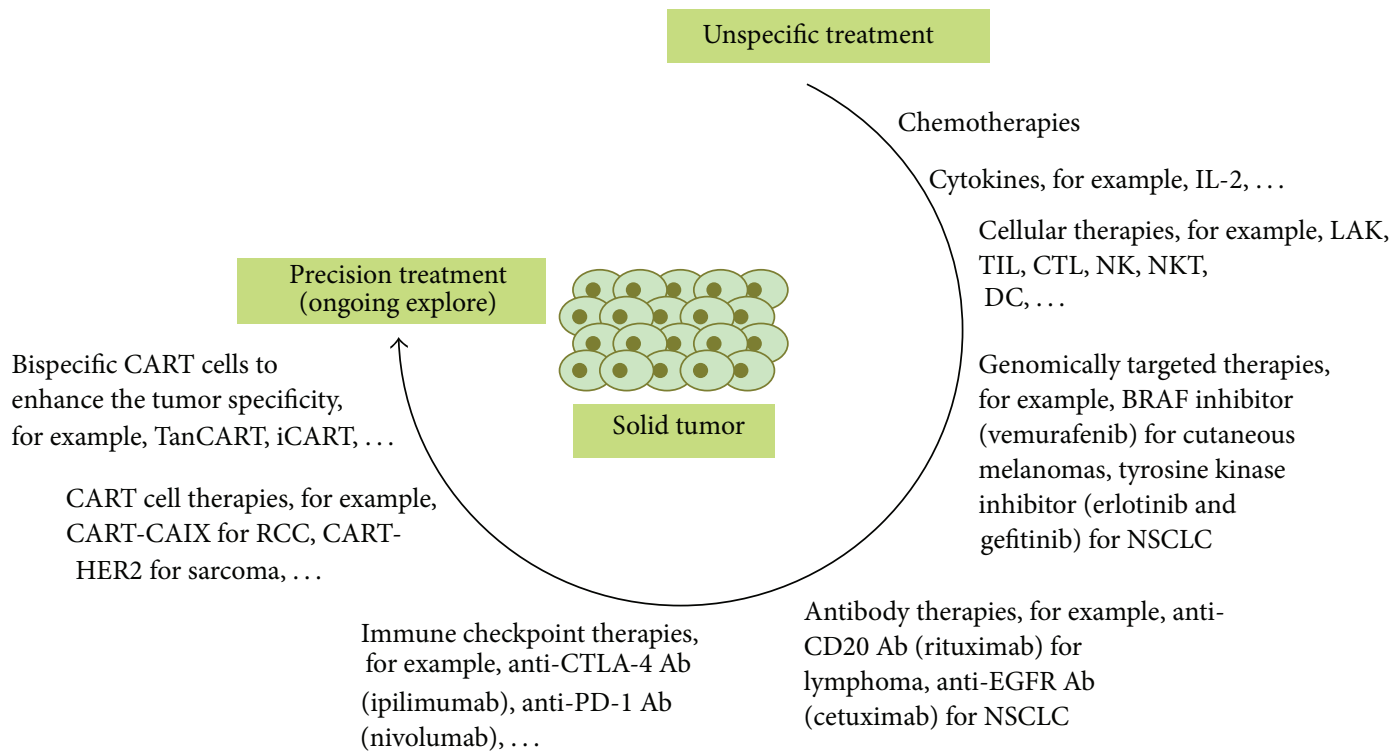

Figure 2: Development of precision treatment for solid tumor. Ab: antibody; CTL: cytotoxic T cells; CTLA-4: cytotoxic T lymphocyteassociated antigen-4; DC: dendritic cells; iCART: inhibitory signal-based antigen-specific CART cells; IL-2: interleukin-2; LAK: lymphokineactivated killer cells; NK: natural killer cells; NKT: natural killer T cells; NSCLC: non-small-cell lung cancer; PD-1: programmed death-1; TanCART: tandem CART cells; TIL: tumor-infiltrating lymphocytes.

therapy. To the best of our knowledge, it is well known that solid tumors can create a complex microenvironment to defend against an attack from the immune system. For example, the antitumor effect of $\mathrm{T}$ cells can be inhibited by expressing PD-1 when it interacts with its ligands PD-L1 and PD-L2 that are expressed on tumor cells and/or stroma cells $[98,99]$. Most in vitro and preclinical data have indicated that the blockade of the interaction between PD-1 and PDL1 or PD-L2 provides a potentially promising approach for cancer immunotherapy by improving the response of $\mathrm{T}$ cells $[99,100]$. Several clinical studies of anti-PD-1 monoclonal antibody have demonstrated the safety and activity for patients with advanced solid tumors, such as melanoma, nonsmall-cell lung cancer, and renal cell cancer [101, 102]. In addition, a phase I clinical study showed evidence for an antitumor effect of anti-PD-L1 antibody against advanced solid tumors [103]. It is promising that two antibodies against PD-1 (pembrolizumab and nivolumab) have been approved by the U.S. Food and Drug Administration in 2014 [58]. Therefore, exploration of CART cells combined with PD-1/PD-L1-specific antibodies is expected to increase the antitumor effect in solid tumors.

Several negative regulators other than PD-1 have been identified and reported to inhibit the response of $\mathrm{T}$ cells to attack against tumors, for example, CTLA-4, T-cell immunoglobulin and mucin-containing protein 3 (TIM-3), lymphocyte-activated gene-3 (LAG-3), T-cell immunoreceptor with Ig and ITIM domains (TIGIT), B and T lymphocyte attenuator (BTLA), and V-domain Ig suppressor of T-cell activation (VISTA) [104]. The continued development of CART-cell therapy combined with inhibitors of these negative regulators could improve their clinical benefit in solid tumors.

\section{CART Cells as a Primary Strategy for Treating Solid Tumors}

Due to economic and medical technological factors, most cancer patients are diagnosed at an advanced disease stage. The strategies for treating patients with advanced solid malignant diseases mainly include surgery, chemotherapy, radiotherapy, targeted therapy, and supportive care, but cancers generally relapse or become refractory, denying patients their best opportunity for treatment. Recent studies indicated that adoptive cell transfer treatments can stimulate and improve the function of the immune system and overcome chemotherapy resistance $[105,106]$. Nevertheless, patients are often first treated by traditional approaches rather than by the adoptive transfer of immune cells.

CART-cell treatment as a primary strategy needs to be implemented urgently to increase the therapeutic benefit for patients with solid tumors. Although experience with the adoptive transfer of CART cells to treat solid tumors remains limited, technological improvements will enhance clinical responses in the future. Several tasks should be addressed, including (1) careful screening of patients to ensure that they have the specific tumor target to reduce the risk of on-target/off-tumor adverse event; (2) suggesting CART-cell therapy as a primary strategy for patients and clinical researchers, alone or in combination with other therapies; (3) establishing the benefit of using CART cells as a first treatment; (4) monitoring and resolving the toxicities in these strategies; and (5) analyzing the clinical response compared with other therapies. In addition, to improve the clinical response and standardize the procedures, largescale, controlled, grouped, and multiple-center clinical trials are of particular importance to implement. On this basis, 
the treatment of solid tumors by CART cells as a primary strategy can be extended.

\section{Conclusions and Perspectives}

Efforts to treat solid tumors with CART cells are ongoing. Considering the recent studies together, treatment with CART cells has been shown to be safe and is thus potential promising for the treatment of solid tumors. However, none of these CART-cell-based strategies has been superior to the existing options, and a number of the challenges and limitations mentioned above must be resolved to ensure better patient benefit and to extend this treatment approach. Based on previous studies, the safety and clinical responses are still the main exploring focuses in the future. CART cells combined with other therapies, such as chemotherapy, radiotherapy, and PD-1/PD-L1 antibodies, will also be relevant. The best clinical responses can be achieved through careful preparation of patients, CART cells and doses, preconditioning regimens, and follow-up treatments. In addition, CART cells will likely be commercialized to increase their convenience and flexibility for patients with solid tumors, or even other malignancies, using streamlined, centralized, and large-scale generation of CART cells from uniform cell sources. These interventions will make treatment with CART cells an effective and routine therapy for solid tumors. In conclusion, although more work is needed to meet the challenges, treatment with CART cells has a significant potential to improve clinical responses in solid tumors.

\section{Conflict of Interests}

The authors declare that there is no conflict of interests regarding the publication of this paper.

\section{Authors' Contribution}

Yelei Guo and Yao Wang equally contributed to the work.

\section{Acknowledgments}

This work was supported by Nursery Innovation Fund (Grant no. 15KMM50), Science and Technology Planning Project of Beijing City (Grant no. Z151100003915076 to Weidong Han), and National Natural Science Foundation of China (no. 31270820 and no. 81230061 to Weidong Han).

\section{References}

[1] M. H. Kershaw, J. A. Westwood, and P. K. Darcy, "Geneengineered T cells for cancer therapy," Nature Reviews Cancer, vol. 13, no. 8, pp. 525-541, 2013.

[2] M. Sadelain, R. Brentjens, and I. Rivière, "The basic principles of chimeric antigen receptor design," Cancer Discovery, vol. 3, no. 4, pp. 388-398, 2013.

[3] J. N. Kochenderfer, M. E. Dudley, S. H. Kassim et al., "Chemotherapy-refractory diffuse large B-cell lymphoma and indolent B-cell malignancies can be effectively treated with autologous $\mathrm{T}$ cells expressing an anti-CD19 chimeric antigen receptor," Journal of Clinical Oncology, vol. 33, no. 6, pp. 540549, 2015.

[4] J. N. Kochenderfer, M. E. Dudley, S. A. Feldman et al., "B-cell depletion and remissions of malignancy along with cytokineassociated toxicity in a clinical trial of anti-CD19 chimericantigen-receptor-transduced T cells," Blood, vol. 119, no. 12, pp. 2709-2720, 2012.

[5] C. U. Louis, B. Savoldo, G. Dotti et al., "Antitumor activity and long-term fate of chimeric antigen receptor-positive $\mathrm{T}$ cells in patients with neuroblastoma," Blood, vol. 118, no. 23, pp. 60506056, 2011.

[6] R. J. Brentjens, M. L. Davila, I. Riviere et al., "CD19-targeted $\mathrm{T}$ cells rapidly induce molecular remissions in adults with chemotherapy-refractory acute lymphoblastic leukemia," Science Translational Medicine, vol. 5, no. 177, Article ID 177ra38, 2013.

[7] C. H. J. Lamers, S. Sleijfer, A. G. Vulto et al., "Treatment of metastatic renal cell carcinoma with autologous T-lymphocytes genetically retargeted against carbonic anhydrase IX: first clinical experience," Journal of Clinical Oncology, vol. 24, no. 13, pp. e20-e22, 2006.

[8] C. H. J. Lamers, S. Sleijfer, S. Van Steenbergen et al., "Treatment of metastatic renal cell carcinoma with CAIX CAR-engineered $\mathrm{T}$ cells: clinical evaluation and management of on-target toxicity," Molecular Therapy, vol. 21, no. 4, pp. 904-912, 2013.

[9] J. R. Park, D. L. Digiusto, M. Slovak et al., "Adoptive transfer of chimeric antigen receptor re-directed cytolytic T lymphocyte clones in patients with neuroblastoma," Molecular Therapy, vol. 15, no. 4, pp. 825-833, 2007.

[10] G. Gross, T. Waks, and Z. Eshhar, "Expression of immunoglobulin-T-cell receptor chimeric molecules as functional receptors with antibody-type specificity," Proceedings of the National Academy of Sciences of the United States of America, vol. 86, no. 24, pp. 10024-10028, 1989.

[11] M. H. Kershaw, J. A. Westwood, L. L. Parker et al., "A phase I study on adoptive immunotherapy using gene-modified T cells for ovarian cancer," Clinical Cancer Research, vol. 12, no. 20, pp. 6106-6115, 2006.

[12] M. A. Pule, B. Savoldo, G. D. Myers et al., "Virus-specific T cells engineered to coexpress tumor-specific receptors: persistence and antitumor activity in individuals with neuroblastoma," Nature Medicine, vol. 14, no. 11, pp. 1264-1270, 2008.

[13] R. A. Morgan, J. C. Yang, M. Kitano, M. E. Dudley, C. M. Laurencot, and S. A. Rosenberg, "Case report of a serious adverse event following the administration of $t$ cells transduced with a chimeric antigen receptor recognizing ERBB2," Molecular Therapy, vol. 18, no. 4, pp. 843-851, 2010.

[14] G. L. Beatty, A. R. Haas, M. V. Maus et al., "Mesothelin-specific chimeric antigen receptor mRNA-engineered $\mathrm{T}$ cells induce anti-tumor activity in solid malignancies," Cancer Immunology Research, vol. 2, no. 2, pp. 112-120, 2014.

[15] N. Ahmed, V. S. Brawley, M. Hegde et al., "Human Epidermal Growth Factor Receptor 2 (HER2) -specific chimeric antigen receptor-modified $\mathrm{T}$ cells for the immunotherapy of HER2positive sarcoma," Journal of Clinical Oncology, vol. 33, no. 15, pp. 1688-1696, 2015.

[16] M. V. Maus, A. R. Haas, G. L. Beatty et al., "T cells expressing chimeric antigen receptors can cause anaphylaxis in humans," Cancer Immunology Research, vol. 1, pp. 26-31, 2013.

[17] S. C. Katz, R. A. Burga, E. McCormack et al., "Phase I hepatic immunotherapy for metastases study of intra-arterial 
chimeric antigen receptor-modified T-cell therapy for $\mathrm{CEA}^{+}$ liver metastases," Clinical Cancer Research, vol. 21, no. 14, pp. 3149-3159, 2015.

[18] X. Tang, Y. Zhou, W. Li et al., "T cells expressing a LMP1specific chimeric antigen receptor mediate antitumor effects against LMP1-positive nasopharyngeal carcinoma cells in vitro and in vivo," Journal of Biomedical Research, vol. 28, no. 6, pp. 468-475, 2014

[19] G. Jakka, P. C. Schuberth, M. Thiel et al., "Antigen-specific in vitro expansion of functional redirected NY-ESO-1-specific human CD8+ T-cells in a cell-free system," Anticancer Research, vol. 33, no. 10, pp. 4189-4201, 2013.

[20] N. Ahmed, V. S. Salsman, E. Yvon et al., "Immunotherapy for osteosarcoma: genetic modification of $\mathrm{T}$ cells overcomes low levels of tumor antigen expression," Molecular Therapy, vol. 17, no. 10, pp. 1779-1787, 2009.

[21] D. Ebb, P. Meyers, H. Grier et al., "Phase II trial of trastuzumab in combination with cytotoxic chemotherapy for treatment of metastatic osteosarcoma with human epidermal growth factor receptor 2 overexpression: a report from the children's oncology group," Journal of Clinical Oncology, vol. 30, no. 20, pp. 25452551, 2012.

[22] M. Sadelain, R. Brentjens, and I. Rivière, "The promise and potential pitfalls of chimeric antigen receptors," Current Opinion in Immunology, vol. 21, no. 2, pp. 215-223, 2009.

[23] S. Kakarla and S. Gottschalk, "CAR T cells for solid tumors: armed and ready to go?" Cancer Journal, vol. 20, no. 2, pp. 151155, 2014.

[24] P. G. Coulie, B. J. Van den Eynde, P. van der Bruggen, and T. Boon, "Tumour antigens recognized by $\mathrm{T}$ lymphocytes: at the core of cancer immunotherapy," Nature Reviews Cancer, vol. 14, no. 2, pp. 135-146, 2014.

[25] N. Vigneron, V. Stroobant, B. J. Van den Eynde, and P. van der Bruggen, "Database of T cell-defined human tumor antigens: the 2013 update," Cancer Immunity, vol. 13, article 15, 2013.

[26] E. F. Fritsch, N. Hacohen, and C. J. Wu, "Personal neoantigen cancer vaccines: the momentum builds," Oncoimmunology, vol. 3, no. 6, Article ID e29311, 2014.

[27] J. H. Sampson, A. B. Heimberger, G. E. Archer et al., "Immunologic escape after prolonged progression-free survival with epidermal growth factor receptor variant III peptide vaccination in patients with newly diagnosed glioblastoma," Journal of Clinical Oncology, vol. 28, no. 31, pp. 4722-4729, 2010.

[28] T. Blankenstein, M. Leisegang, W. Uckert, and H. Schreiber, "Targeting cancer-specific mutations by $\mathrm{T}$ cell receptor gene therapy," Current Opinion in Immunology, vol. 33, pp. 112-119, 2015.

[29] F. Turatti, M. Figini, E. Balladore et al., "Redirected activity of human antitumor chimeric immune receptors is governed by antigen and receptor expression levels and affinity of interaction," Journal of Immunotherapy, vol. 30, no. 7, pp. 684-693, 2007.

[30] M. Chmielewski, A. Hombach, C. Heuser, G. P. Adams, and H. Abken, "T cell activation by antibody-like immunoreceptors: increase in affinity of the single-chain fragment domain above threshold does not increase $\mathrm{T}$ cell activation against antigenpositive target cells but decreases selectivity," The Journal of Immunology, vol. 173, no. 12, pp. 7647-7653, 2004.

[31] X. Liu, S. Jiang, C. Fang et al., "Affinity-tuned ErbB2 or EGFR chimeric antigen receptor $\mathrm{T}$ cells exhibit an increased therapeutic index against tumors in mice," Cancer Research, vol. 75, no. 17, pp. 3596-3607, 2015.
[32] H. G. Caruso, L. V. Hurton, A. Najjar et al., “Tuning sensitivity of CAR to EGFR density limits recognition of normal tissue while maintaining potent antitumor activity," Cancer Research, vol. 75, no. 17, pp. 3505-3518, 2015.

[33] C. H. J. Lamers, R. Willemsen, P. van Elzakker et al., "Immune responses to transgene and retroviral vector in patients treated with ex vivo-engineered T cells," Blood, vol. 117, no. 1, pp. 72-82, 2011.

[34] A. H. Long, W. M. Haso, J. F. Shern et al., "4-1BB costimulation ameliorates $\mathrm{T}$ cell exhaustion induced by tonic signaling of chimeric antigen receptors," Nature Medicine, vol. 21, no. 6, pp. 581-590, 2015.

[35] H. Zhang, K. M. Snyder, M. M. Suhoski et al., "4-1BB is superior to $\mathrm{CD} 28$ costimulation for generating $\mathrm{CD}^{+}$cytotoxic lymphocytes for adoptive immunotherapy," The Journal of Immunology, vol. 179, no. 7, pp. 4910-4918, 2007.

[36] C. Carpenito, M. C. Milone, R. Hassan et al., "Control of large, established tumor xenografts with genetically retargeted human T cells containing CD28 and CD137 domains," Proceedings of the National Academy of Sciences of the United States of America, vol. 106, no. 9, pp. 3360-3365, 2009.

[37] X.-S. Zhong, M. Matsushita, J. Plotkin, I. Riviere, and M. Sadelain, "Chimeric antigen receptors combining $4-1 \mathrm{BB}$ and $\mathrm{CD} 28$ signaling domains augment $\mathrm{PI}_{3}$ kinase/AKT/Bcl- $\mathrm{X}_{L}$ activation and $\mathrm{CD}^{8+} \mathrm{T}$ cell-mediated tumor eradication," Molecular Therapy, vol. 18, no. 2, pp. 413-420, 2010.

[38] A. A. Hombach, G. Rappl, and H. Abken, "Arming cytokineinduced killer cells with chimeric antigen receptors: CD28 outperforms combined CD28-OX40 'super-stimulation,' Molecular Therapy, vol. 21, no. 12, pp. 2268-2277, 2013.

[39] Y. Zhao, Q. J. Wang, S. Yang et al., "A herceptin-based chimeric antigen receptor with modified signaling domains leads to enhanced survival of transduced T lymphocytes and antitumor activity," The Journal of Immunology, vol. 183, no. 9, pp. 5563$5574,2009$.

[40] S. L. Maude, N. Frey, P. A. Shaw et al., "Chimeric antigen receptor T cells for sustained remissions in leukemia," The New England Journal of Medicine, vol. 371, no. 16, pp. 1507-1517, 2014.

[41] D. W. Lee, J. N. Kochenderfer, M. Stetler-Stevenson et al., "T cells expressing CD19 chimeric antigen receptors for acute lymphoblastic leukaemia in children and young adults: a phase 1 dose-escalation trial," The Lancet, vol. 385, no. 9967, pp. 517528,2015

[42] M. C. Milone, J. D. Fish, C. Carpenito et al., "Chimeric receptors containing CD137 signal transduction domains mediate enhanced survival of T cells and increased antileukemic efficacy in vivo," Molecular Therapy, vol. 17, no. 8, pp. 1453-1464, 2009.

[43] C. M. Kowolik, M. S. Topp, S. Gonzalez et al., "CD28 costimulation provided through a CD19-specific chimeric antigen receptor enhances in vivo persistence and antitumor efficacy of adoptively transferred T cells," Cancer Research, vol. 66, no. 22, pp. 10995-11004, 2006.

[44] H. M. Finney, A. N. Akbar, and A. D. G. Lawson, "Activation of resting human primary $\mathrm{T}$ cells with chimeric receptors: costimulation from CD28, inducible costimulator, CD134, and CD137 in series with signals from the TCR $\zeta$ chain," The Journal of Immunology, vol. 172, no. 1, pp. 104-113, 2004.

[45] C. S. Hinrichs, Z. A. Borman, L. Cassard et al., "Adoptively transferred effector cells derived from naïve rather than central memory $\mathrm{CD}^{+}$T cells mediate superior antitumor immunity," Proceedings of the National Academy of Sciences of the United States of America, vol. 106, no. 41, pp. 17469-17474, 2009. 
[46] C. A. Klebanoff, L. Gattinoni, P. Torabi-Parizi et al., "Central memory self/tumor-reactive $\mathrm{CD}^{+} \mathrm{T}$ cells confer superior antitumor immunity compared with effector memory T cells," Proceedings of the National Academy of Sciences of the United States of America, vol. 102, no. 27, pp. 9571-9576, 2005.

[47] C. H. J. Lamers, S. van Steenbergen-Langeveld, M. van Brakel et al., "T cell receptor-engineered T cells to treat solid tumors: T cell processing toward optimal T cell fitness," Human Gene Therapy Methods, vol. 25, no. 6, pp. 345-357, 2014.

[48] C. S. Hinrichs, R. Spolski, C. M. Paulos et al., "IL-2 and IL-21 confer opposing differentiation programs to $\mathrm{CD} 8^{+} \mathrm{T}$ cells for adoptive immunotherapy," Blood, vol. 111, no. 11, pp. 5326-5333, 2008.

[49] S. Kaneko, S. Mastaglio, A. Bondanza et al., "IL-7 and IL-15 allow the generation of suicide gene-modified alloreactive selfrenewing central memory human T lymphocytes," Blood, vol. 113, no. 5, pp. 1006-1015, 2009.

[50] N. Pouw, E. Treffers-Westerlaken, A. Mondino, C. Lamers, and R. Debets, “TCR gene-engineered T cell: limited T cell activation and combined use of IL-15 and IL-21 ensure minimal differentiation and maximal antigen-specificity," Molecular Immunology, vol. 47, no. 7-8, pp. 1411-1420, 2010.

[51] C. E. Brown, R. P. Vishwanath, B. Aguilar et al., "Tumorderived chemokine MCP-1/CCL2 is sufficient for mediating tumor tropism of adoptively transferred T cells," The Journal of Immunology, vol. 179, no. 5, pp. 3332-3341, 2007.

[52] U. Palendira, R. Chinn, W. Raza et al., "Selective accumulation of virus-specific CD8+ T cells with unique homing phenotype within the human bone marrow," Blood, vol. 112, no. 8, pp. 3293$3302,2008$.

[53] B. Jena, G. Dotti, and L. J. N. Cooper, "Redirecting T-cell specificity by introducing a tumor-specific chimeric antigen receptor," Blood, vol. 116, no. 7, pp. 1035-1044, 2010.

[54] M. H. Kershaw, G. Wang, J. A. Westwood et al., "Redirecting migration of $\mathrm{T}$ cells to chemokine secreted from tumors by genetic modification with CXCR2," Human Gene Therapy, vol. 13, no. 16, pp. 1971-1980, 2002.

[55] A. Di Stasi, B. De Angelis, C. M. Rooney et al., “T lymphocytes coexpressing CCR4 and a chimeric antigen receptor targeting CD30 have improved homing and antitumor activity in a Hodgkin tumor model," Blood, vol. 113, no. 25, pp. 6392-6402, 2009.

[56] M. D. Vesely, M. H. Kershaw, R. D. Schreiber, and M. J. Smyth, "Natural innate and adaptive immunity to cancer," Annual Review of Immunology, vol. 29, pp. 235-271, 2011.

[57] J. A. Joyce and D. T. Fearon, "T cell exclusion, immune privilege, and the tumor microenvironment," Science, vol. 348, no. 6230, pp. 74-80, 2015.

[58] P. Sharma and J. P. Allison, "The future of immune checkpoint therapy," Science, vol. 348, no. 6230, pp. 56-61, 2015.

[59] F. Liu, R. Lang, J. Zhao et al., "CD8 $8^{+}$cytotoxic T cell and FOXP3 ${ }^{+}$ regulatory $\mathrm{T}$ cell infiltration in relation to breast cancer survival and molecular subtypes," Breast Cancer Research and Treatment, vol. 130, no. 2, pp. 645-655, 2011.

[60] T. H. Kang, C.-P. Mao, S. Y. Lee et al., "Chemotherapy acts as an adjuvant to convert the tumor microenvironment into a highly permissive state for vaccination-induced antitumor immunity," Cancer Research, vol. 73, no. 8, pp. 2493-2504, 2013.

[61] P. Muranski, A. Boni, C. Wrzesinski et al., "Increased intensity lymphodepletion and adoptive immunotherapy-how far can we go?" Nature Clinical Practice Oncology, vol. 3, no. 12, pp. 668$681,2006$.
[62] M. Anraku, T. Tagawa, L. Wu et al., "Synergistic antitumor effects of regulatory $\mathrm{T}$ cell blockade combined with pemetrexed in murine malignant mesothelioma," The Journal of Immunology, vol. 185, no. 2, pp. 956-966, 2010.

[63] C. T. Garnett, J. Schlom, and J. W. Hodge, "Combination of docetaxel and recombinant vaccine enhances T-cell responses and antitumor activity: effects of docetaxel on immune enhancement," Clinical Cancer Research, vol. 14, no. 11, pp. 3536-3544, 2008.

[64] K. L. Knutson, Y. Dang, H. Lu et al., "IL-2 immunotoxin therapy modulates tumor-associated regulatory $\mathrm{T}$ cells and leads to lasting immune-mediated rejection of breast cancers in neutransgenic mice," The Journal of Immunology, vol. 177, no. 1, pp. 84-91, 2006.

[65] G. C. Cesana, G. DeRaffele, S. Cohen et al., "Characterization of $\mathrm{CD}^{+} \mathrm{CD} 25^{+}$regulatory $\mathrm{T}$ cells in patients treated with high-dose interleukin-2 for metastatic melanoma or renal cell carcinoma," Journal of Clinical Oncology, vol. 24, no. 7, pp. 1169$1177,2006$.

[66] M. E. Dudley, J. R. Wunderlich, P. F. Robbins et al., "Cancer regression and autoimmunity in patients after clonal repopulation with antitumor lymphocytes," Science, vol. 298, no. 5594, pp. 850-854, 2002.

[67] E. B. Golden, I. Pellicciotta, S. Demaria, M. H. BarcellosHoff, and S. C. Formenti, "The convergence of radiation and immunogenic cell death signaling pathways," Frontiers in Oncology, vol. 2, article 88, Article ID Article 88, 2012.

[68] D. R. Green, T. Ferguson, L. Zitvogel, and G. Kroemer, "Immunogenic and tolerogenic cell death," Nature Reviews Immunology, vol. 9, no. 5, pp. 353-363, 2009.

[69] M. Obeid, T. Panaretakis, N. Joza et al., "Calreticulin exposure is required for the immunogenicity of $\gamma$-irradiation and UVC light-induced apoptosis," Cell Death and Differentiation, vol. 14, no. 10, pp. 1848-1850, 2007.

[70] M. Obeid, A. Tesniere, T. Panaretakis et al., "Ecto-calreticulin in immunogenic chemotherapy," Immunological Reviews, vol. 220, no. 1, pp. 22-34, 2007.

[71] V. Shahabi, M. A. Postow, D. Tuck, and J. D. Wolchok, "Immunepriming of the tumor microenvironment by radiotherapy: rationale for combination with immunotherapy to improve anticancer efficacy," American Journal of Clinical Oncology: Cancer Clinical Trials, vol. 38, no. 1, pp. 90-97, 2015.

[72] L. Apetoh, F. Ghiringhelli, A. Tesniere et al., "Toll-like receptor 4-dependent contribution of the immune system to anticancer chemotherapy and radiotherapy," Nature Medicine, vol. 13, no. 9, pp. 1050-1059, 2007.

[73] B. C. Burnette, H. Liang, Y. Lee et al., "The efficacy of radiotherapy relies upon induction of type I interferon-dependent innate and adaptive immunity," Cancer Research, vol. 71, no. 7, pp. 2488-2496, 2011.

[74] Y. Lee, S. L. Auh, Y. Wang et al., "Therapeutic effects of ablative radiation on local tumor require $\mathrm{CD} 8^{+} \mathrm{T}$ cells: changing strategies for cancer treatment," Blood, vol. 114, no. 3, pp. 589595, 2009.

[75] E. A. Reits, J. W. Hodge, C. A. Herberts et al., "Radiation modulates the peptide repertoire, enhances MHC class I expression, and induces successful antitumor immunotherapy," Journal of Experimental Medicine, vol. 203, no. 5, pp. 1259-1271, 2006.

[76] M. Chakraborty, S. I. Abrams, K. Camphausen et al., "Irradiation of tumor cells up-regulates Fas and enhances CTL lytic activity and CTL adoptive immunotherapy," The Journal of Immunology, vol. 170, no. 12, pp. 6338-6347, 2003. 
[77] M. G. Ruocco, K. A. Pilones, N. Kawashima et al., "Suppressing T cell motility induced by anti-CTLA- 4 monotherapy improves antitumor effects," The Journal of Clinical Investigation, vol. 122, no. 10, pp. 3718-3730, 2012.

[78] K. M. Mahoney, P. D. Rennert, and G. J. Freeman, "Combination cancer immunotherapy and new immunomodulatory targets," Nature Reviews Drug Discovery, vol. 14, no. 8, pp. 561-584, 2015.

[79] N. A. Bhowmick, E. G. Neilson, and H. L. Moses, "Stromal fibroblasts in cancer initiation and progression," Nature, vol. 432, no. 7015, pp. 332-337, 2004.

[80] A. Orimo, P. B. Gupta, D. C. Sgroi et al., "Stromal fibroblasts present in invasive human breast carcinomas promote tumor growth and angiogenesis through elevated SDF-1/CXCL12 secretion," Cell, vol. 121, no. 3, pp. 335-348, 2005.

[81] A. M. Santos, J. Jung, N. Aziz, J. L. Kissil, and E. Puré, “Targeting fibroblast activation protein inhibits tumor stromagenesis and growth in mice," The Journal of Clinical Investigation, vol. 119, no. 12, pp. 3613-3625, 2009.

[82] T.-K. Ito, G. Ishii, H. Chiba, and A. Ochiai, "The VEGF angiogenic switch of fibroblasts is regulated by MMP-7 from cancer cells," Oncogene, vol. 26, no. 51, pp. 7194-7203, 2007.

[83] Y. Zhang, H. Tang, J. Cai et al., "Ovarian cancer-associated fibroblasts contribute to epithelial ovarian carcinoma metastasis by promoting angiogenesis, lymphangiogenesis and tumor cell invasion," Cancer Letters, vol. 303, no. 1, pp. 47-55, 2011.

[84] Z. G. Fridlender, J. Sun, S. Kim et al., "Polarization of tumorassociated neutrophil phenotype by TGF- $\beta$ : 'N1' versus 'N2' TAN,” Cancer Cell, vol. 16, no. 3, pp. 183-194, 2009.

[85] E. Tran, D. Chinnasamy, Z. Yu et al., "Immune targeting of fibroblast activation protein triggers recognition of multipotent bone marrow stromal cells and cachexia," Journal of Experimental Medicine, vol. 210, no. 6, pp. 1125-1135, 2013.

[86] S. Kakarla, K. K. H. Chow, M. Mata et al., "Antitumor effects of chimeric receptor engineered human T cells directed to tumor stroma," Molecular Therapy, vol. 21, no. 8, pp. 1611-1620, 2013.

[87] P. C. Schuberth, C. Hagedorn, S. M. Jensen et al., "Treatment of malignant pleural mesothelioma by fibroblast activation protein-specific re-directed T cells," Journal of Translational Medicine, vol. 11, article 187, 2013.

[88] L. S. Wang, A. Lo, J. Scholler et al., "Targeting fibroblast activation protein in tumor stroma with chimeric antigen receptor T cells can inhibit tumor growth and augment host immunity without severe toxicity," Cancer Immunology Research, vol. 2, no. 2, pp. 154-166, 2014.

[89] K. Fousek and N. Ahmed, "The Evolution of T-cell therapies for solid malignancies," Clinical Cancer Research, vol. 21, no. 15, pp. 3384-3392, 2015.

[90] C. C. Kloss, M. Condomines, M. Cartellieri, M. Bachmann, and M. Sadelain, "Combinatorial antigen recognition with balanced signaling promotes selective tumor eradication by engineered $\mathrm{T}$ cells," Nature Biotechnology, vol. 31, no. 1, pp. 71-75, 2013.

[91] V. D. Fedorov, M. Themeli, and M. Sadelain, "PD-1- and CTLA-4-based inhibitory chimeric antigen receptors (iCARs) divert off-target immunotherapy responses," Science Translational Medicine, vol. 5, no. 215, Article ID 215ral72, 2013.

[92] S. Srivastava and S. R. Riddell, "Engineering CAR-T cells: design concepts," Trends in Immunology, vol. 36, no. 8, pp. 494-502, 2015.

[93] Z. Grada, M. Hegde, T. Byrd et al., "TanCAR: a novel bispecific chimeric antigen receptor for cancer immunotherapy," Molecular Therapy-Nucleic Acids, vol. 2, article e105, 2013.
[94] C. Yee, J. A. Thompson, D. Byrd et al., "Adoptive T cell therapy using antigen-specific $\mathrm{CD}^{+} \mathrm{T}$ cell clones for the treatment of patients with metastatic melanoma: in vivo persistence, migration, and antitumor effect of transferred T cells," Proceedings of the National Academy of Sciences of the United States of America, vol. 99, no. 25, pp. 16168-16173, 2002.

[95] S. Khaleghi, F. Rahbarizadeh, D. Ahmadvand, M. J. Rasaee, and P. Pognonec, "A caspase 8-based suicide switch induces apoptosis in nanobody-directed chimeric receptor expressing T cells," International Journal of Hematology, vol. 95, no. 4, pp. 434-444, 2012.

[96] V. Hoyos, B. Savoldo, C. Quintarelli et al., "Engineering CD19specific T lymphocytes with interleukin-15 and a suicide gene to enhance their anti-lymphoma/leukemia effects and safety," Leukemia, vol. 24, no. 6, pp. 1160-1170, 2010.

[97] L. E. Budde, C. Berger, Y. Lin et al., "Combining a CD20 chimeric antigen receptor and an inducible caspase 9 suicide switch to improve the efficacy and safety of T cell adoptive immunotherapy for lymphoma," PLoS ONE, vol. 8, no. 12, Article ID e82742, 2013.

[98] G. J. Freeman, A. J. Long, Y. Iwai et al., "Engagement of the PD-1 immunoinhibitory receptor by a novel B7 family member leads to negative regulation of lymphocyte activation," The Journal of Experimental Medicine, vol. 192, no. 7, pp. 1027-1034, 2000.

[99] H. Dong, S. E. Strome, D. R. Salomao et al., "Tumor-associated B7-H1 promotes T-cell apoptosis: a potential mechanism of immune evasion," Nature Medicine, vol. 8, no. 8, pp. 793-800, 2002.

[100] Y. Iwai, M. Ishida, Y. Tanaka, T. Okazaki, T. Honjo, and N. Minato, "Involvement of PD-L1 on tumor cells in the escape from host immune system and tumor immunotherapy by PDL1 blockade," Proceedings of the National Academy of Sciences of the United States of America, vol. 99, no. 19, pp. 12293-12297, 2002.

[101] S. L. Topalian, F. S. Hodi, J. R. Brahmer et al., "Safety, activity, and immune correlates of anti-PD-1 antibody in cancer," The New England Journal of Medicine, vol. 366, no. 26, pp. 24432454, 2012.

[102] J. R. Brahmer, C. G. Drake, I. Wollner et al., "Phase I study of single-agent anti-programmed death-1 (MDX-1106) in refractory solid tumors: safety, clinical activity, pharmacodynamics, and immunologic correlates," Journal of Clinical Oncology, vol. 28, no. 19, pp. 3167-3175, 2010.

[103] S. L. Topalian, C. G. Drake, and D. M. Pardoll, "Targeting the PD-1/B7-H1(PD-L1) pathway to activate anti-tumor immunity," Current Opinion in Immunology, vol. 24, no. 2, pp. 207-212, 2012.

[104] I. Le Mercier, J. L. Lines, and R. J. Noelle, "Beyond CTLA-4 and $\mathrm{PD}-1$, the generation $\mathrm{Z}$ of negative checkpoint regulators," Frontiers in Immunology, vol. 6, article 418, 2015.

[105] A. G. Niethammer, H. Wodrich, M. Loeffler et al., "Multidrug resistance-1 (MDR-1): a new target for T cell-based immunotherapy," The FASEB Journal, vol. 19, no. 1, pp. 158-159, 2005.

[106] P. Liu, L. Chen, and X. Huang, "The antitumor effects of CIK cells combined with docetaxel against drug-resistant lung adenocarcinoma cell line SPC-A1/DTX in vitro and in vivo," Cancer Biotherapy and Radiopharmaceuticals, vol. 24, no. 1, pp. 91-98, 2009. 


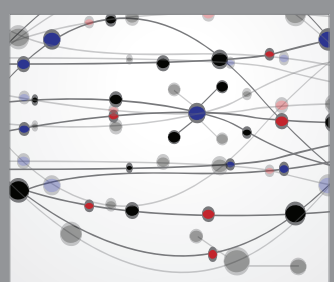

The Scientific World Journal
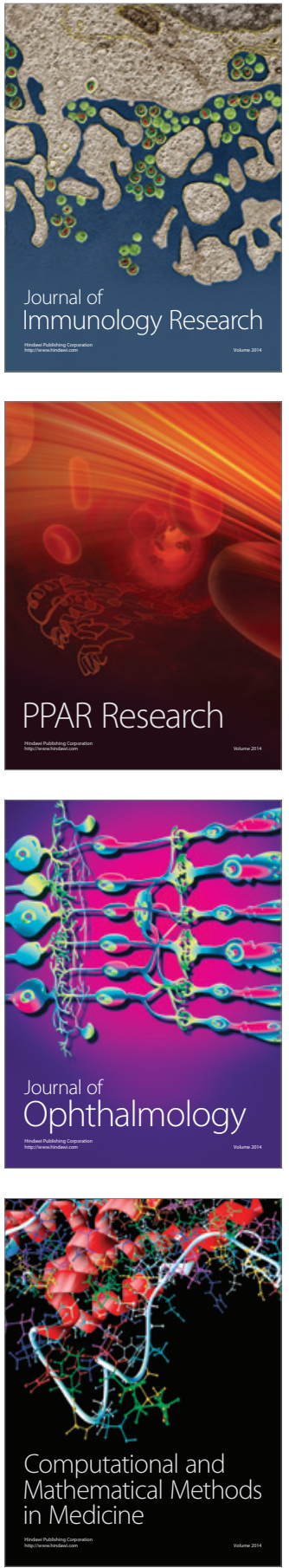

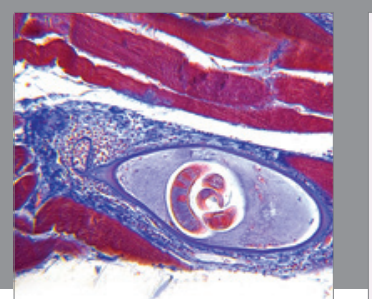

Gastroenterology Research and Practice

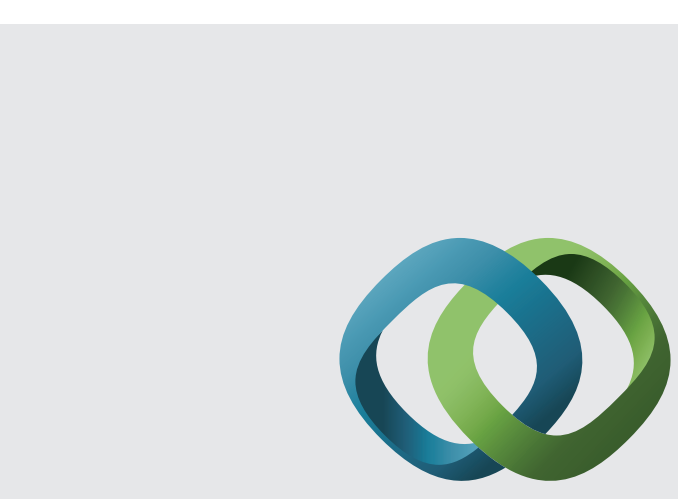

\section{Hindawi}

Submit your manuscripts at

http://www.hindawi.com
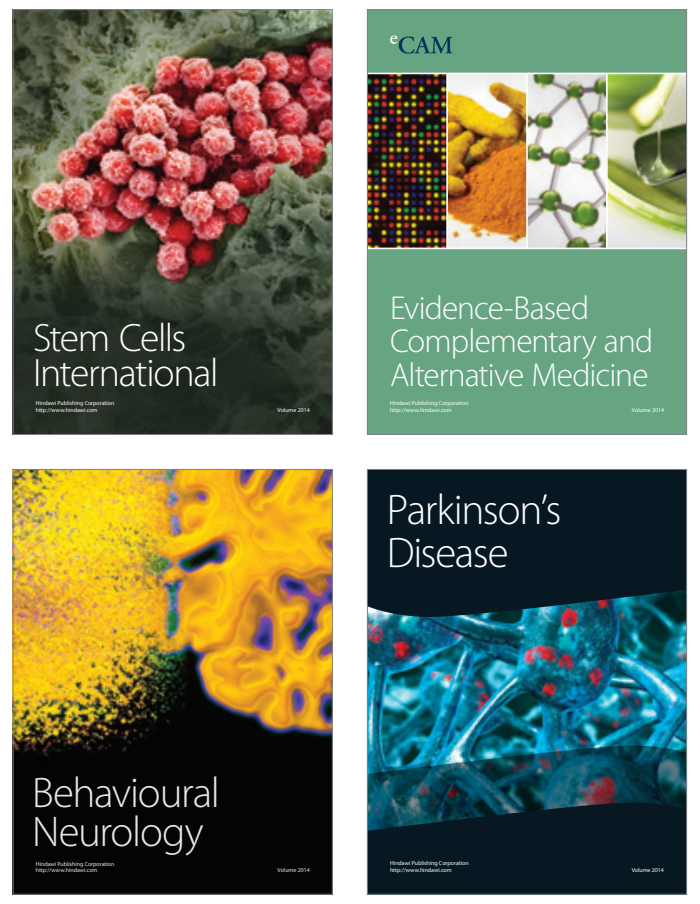
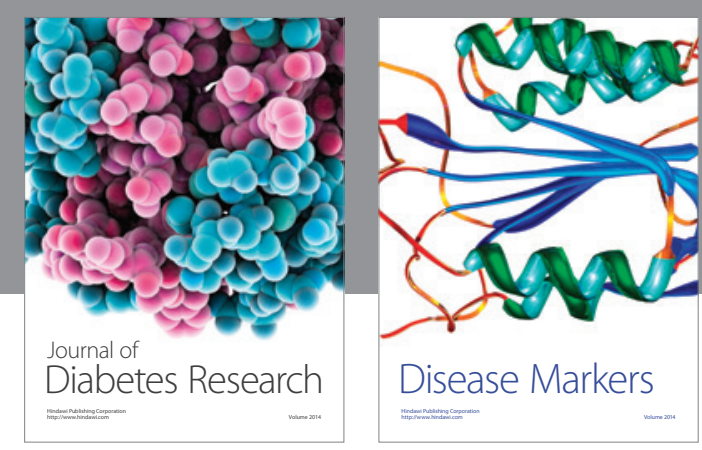

Disease Markers
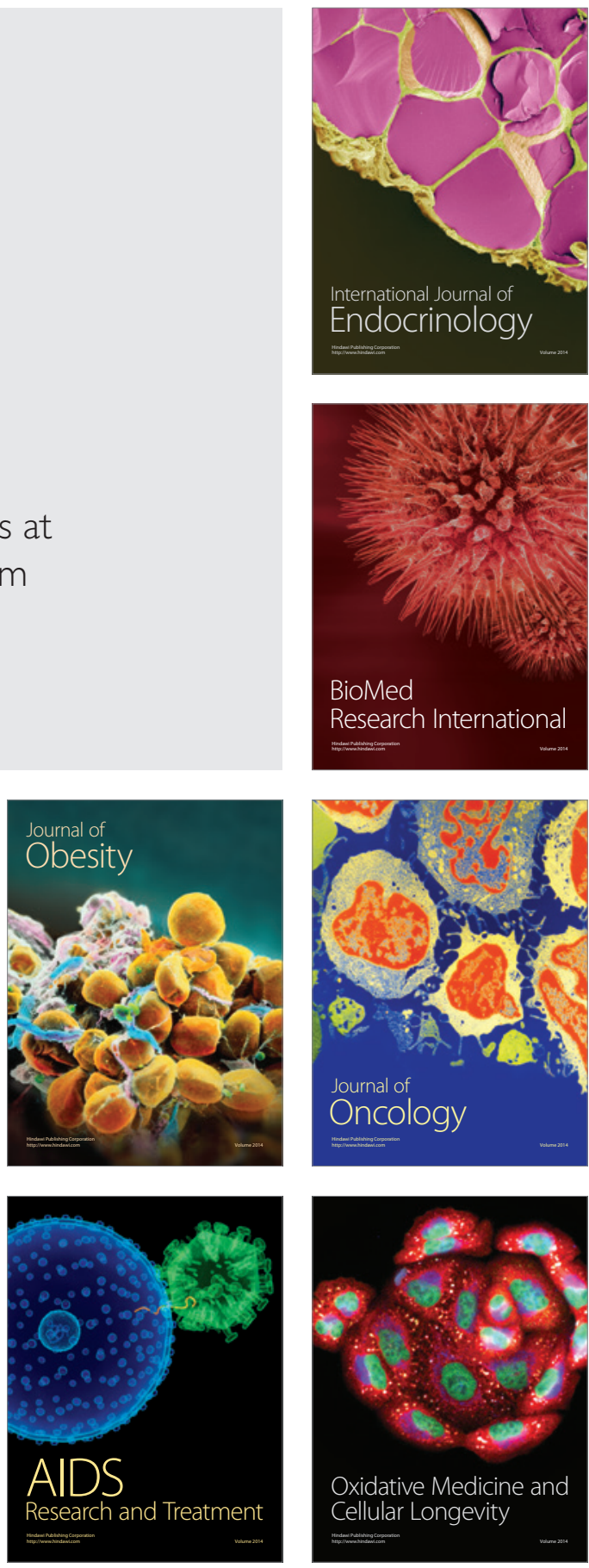